\title{
An IVF baby with neonatal lupus erythematosus
}

\section{Manouri P Senanayake ${ }^{1}$ and Prasad Kumarsinghe ${ }^{2}$}

\section{Introduction}

We report an infant with neonatal lupus erythematosus (NLE) born following in vitro fertilisation (IVF) to a mother who was unaware of an autoimmune illness in herself. NLE is rare in the general population but the literature shows at least seven other IVF babies with this condition $[1,2,3]$. Hormonal manipulation for ovulation induction causing a flare-up of lupus activity is a possible explanation.

\section{Case report}

A baby girl weighing $2.55 \mathrm{~kg}$ was born by caesarean section following an uncomplicated gestational period of 36 weeks and 5 days. The pregnancy had been assisted by ovulation induction and IVF. Apart from antenatally diagnosed acquired hypothyroidism for which the mother was on replacement therapy, she appeared healthy. Medical investigations performed before IVF did not include screening for SLE.

The baby was diagnosed to have congenital hypothyroidism because thyroid stimulating hormone (TSH) levels were $9.3 \mathrm{miu} / \mathrm{ml}$ and $9.4 \mathrm{miu} / \mathrm{ml}$ (normal reference $<8.8 \mathrm{miu} / \mathrm{ml}$ ) at age 16 and 22 days. When treated with thyroxine $12.5 \mathrm{mg}$ /day TSH fell to $4.34 \mathrm{miu} / \mathrm{ml}$.

At the age of 4 weeks a reddish brown, slightly elevated, well defined pigmentation was noticed bilaterally in the preauricular regions. The rash progressed to involve the entire forehead and bridge of nose by 13 weeks. The cheeks, scalp, trunk and limbs were unaffected. Cardiovascular and other systems were clinically normal and she continued to thrive and develop normally. The mother complained of arthralgia and lassitude but had no abnormal physical signs.

When the baby was 13 weeks old serological investigations were performed on both baby and mother. The baby's results did not show either Ro-SSA antibody, or La- SSB antibody and the electrocardiogram, and hepatic and haematologic investigations were normal. The antinuclear antibody and Ro-SSA antibody were positive in the mother. Her serology was negative for La-SSB antibody and antidouble stranded DNA. Mother's ESR was $23 \mathrm{~mm}$.
The rash (figure 1) began fading spontaneously from the age of 7 months and disappeared completely by 9 months.

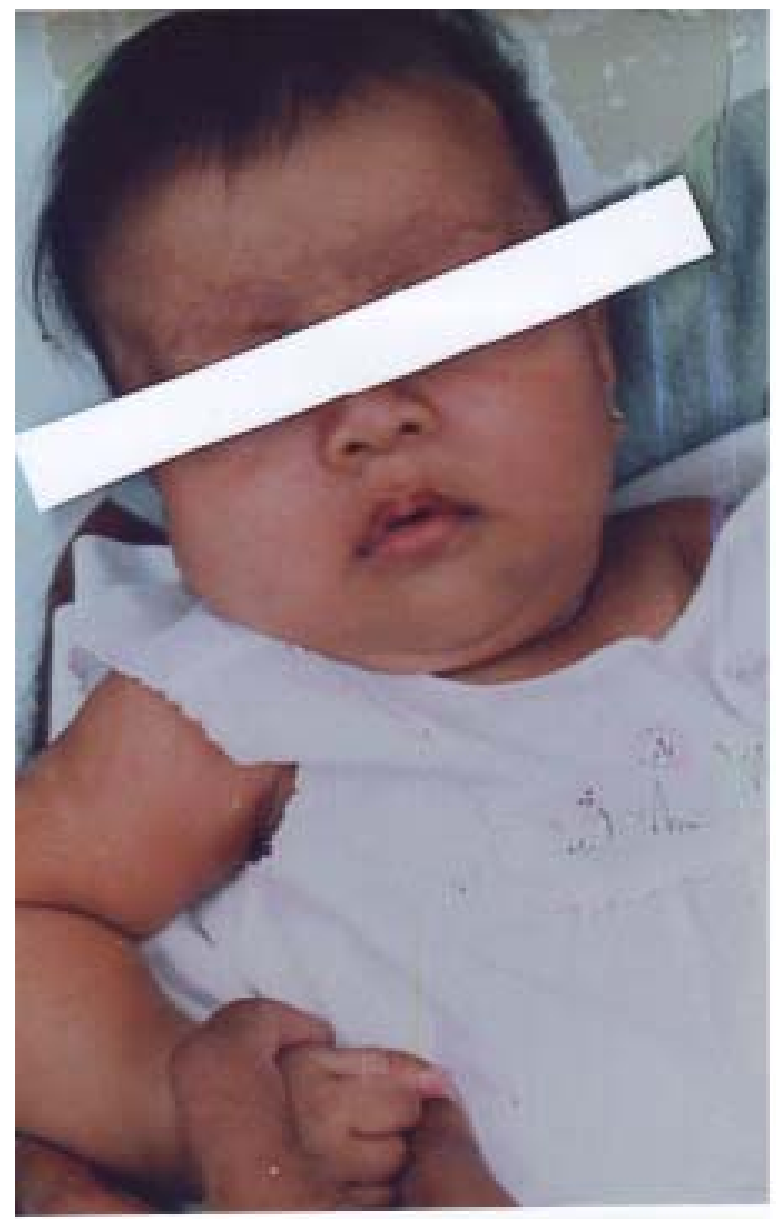

Figure 1. Skin lesion in neonatal lupus erythematosus: brownish plaques on forehead at 13 weeks.

\section{Discussion}

NLE is a rare autoimmune syndrome caused by passively transferred maternal auto-antibodies that react with skin and cardiac muscle. The characteristic rash resolves spontaneously during infancy but cardiac involvement causes lasting damage. Congenital heart block of varying severity caused by fibrosis of the bundle

${ }^{1}$ Department of Paediatrics, Faculty of Medicine, Colombo, and ${ }^{2}$ Dermatology Unit, Colombo North General Hospital, Ragama, Sri Lanka.

Correspondence: MPS, e-mail: <manouri.senanayake@gmail.com>. Received 13 March and revised version accepted 7 August 2008. Conflicts of interest: none declared. 
of His, haemolytic anaemia, thrombocytopenia or hepatitis are noted in a minority of infants. The transient transplacental IgG antibodies are commonly anti Ro/SS-A, and sometimes anti $\mathrm{La} / \mathrm{SS}-\mathrm{B}$.

NLE often brings to light latent or obvious autoimmune connective tissue disorder in the mother. Even if she is asymptomatic, the risk of developing systemic lupus erythematosus (SLE), subacute cutaneous lupus erythematosus or Sjogren's disease in the future remains.

In our report two major criteria stipulated by the American College of Rheumatology ie. the characteristic rash in the neonate and maternal antibodies to Ro-SSB were positive, confirming the diagnosis.

Literature retrieved from Pub Med database showed reports of 7 other cases of NLE following ovulation induction and IVF. Flare-up of lupus activity in women following ovulation induction is documented and rates are higher after gonadotrophins than after clomiphene therapy $[3,4]$. Awareness of this and its associated maternal and fetal complications will increase the safety of artificial reproductive technologies in women with SLE [5].

\section{References}

1. Kecelj N, Vizjak A, Dragos V, Lunder T. Neonatal erythematous lupus - case report. Acta Dermatoven APA 2003; 12: 137-42.

2. Fesslova V, Mannarino S, Salice P, Boschetto C, Trespidi L, Acaia B, et al. Neonatal lupus: fetal myocarditis progressing to atrioventricular block in triplets. Lupus 2003; 12: 775-8.

3. Guballa N, Sammaritano L, Schwartzman S, Buyon J, Lockshin MD. Ovulation induction and in vitro fertilization in systemic lupus erythematosus and antiphospholipid syndrome. Arthritis and Rheumatism 2004; 43: 550-6.

4. Le Thi Huong D, Weschsler B, Piette JC. Ovulation induction therapy and systemic lupus erythematosus. Annales de Medicine Interne 2003; 154: 45-50.

5. Lockshin MD, Sammaritano LR. Lupus pregnancy. Autoimmunity 2003; 36: 33-40. 